\title{
Efficacy of Speed, Agility and Quickness Training with and without Equipment on Athletic Performance Parameters - A Randomized Control Trial
}

\author{
Umair Anwer ${ }^{1}$, Shibili Nuhmani ${ }^{2, *}$, Saurabh Sharma ${ }^{3}$, Mohd Arshad Bari ${ }^{4}$, Shaji John Kachanathu ${ }^{5}$, \\ Turki Saeed Abualait ${ }^{2}$

\begin{abstract}
${ }^{1}$ Department of Rehabilitation Sciences, Jamia Hamdard, New Delhi, India ${ }^{2}$ Department of Physical Therapy, College of Applied Medical Sciences, Imam Abdulrahman Bin Faisal University, Dammam, K.S.A. ${ }^{3}$ Centre for Physiotherapy and Rehabilitation Sciences, Jamia Millia Islamia, New Delhi, India ${ }^{4}$ Department of Physical Education, Aligarh Muslim University, Aligarh, India

${ }^{5}$ Department of Rehabilitation Health Sciences, College of Applied Medical Sciences, King Saud University, Riyadh, K.S.A.
\end{abstract}

Received December 16, 2020; Revised February 4, 2021; Accepted February 24, 2021

\section{Cite This Paper in the following Citation Styles}

(a): [1] Umair Anwer, Shibili Nuhmani, Saurabh Sharma, Mohd Arshad Bari, Shaji John Kachanathu, Turki Saeed Abualait, "Efficacy of Speed, Agility and Quickness Training with and without Equipment on Athletic Performance Parameters - A Randomized Control Trial," International Journal of Human Movement and Sports Sciences, Vol. 9, No. 2, pp. 194-202, 2021. DOI: $10.13189 /$ saj.2021.090205.

(b): Umair Anwer, Shibili Nuhmani, Saurabh Sharma, Mohd Arshad Bari, Shaji John Kachanathu, Turki Saeed Abualait (2021). Efficacy of Speed, Agility and Quickness Training with and without Equipment on Athletic Performance Parameters A Randomized Control Trial. International Journal of Human Movement and Sports Sciences, 9(2), 194-202. DOI: 10.13189/saj.2021.090205.

Copyright $(2021$ by authors, all rights reserved. Authors agree that this article remains permanently open access under the terms of the Creative Commons Attribution License 4.0 International License

\begin{abstract}
Speed, agility and quickness (SAQ) are the key determinants in soccer which enable the player to address decisive situations. Therefore the objective of this study is to investigate the efficacy of the SAQ training with and without specialized training equipment on sports performance parameters in amateur soccer players. In this study, 64 amateur male soccer players between the ages of 18-25 were recruited and randomized into the experimental group and control group. The experimental group received SAQ training with specialized equipment whereas the control group received SAQ training without equipment for six weeks (three times/ week). The study adopted a pretest-posttest design. Vertical jump test, 20-meter sprint test and Illinois agility test were the outcome measures. Both groups were significantly improved $(\mathrm{p}<0.05)$ from pre to post-training in all sports performance measures. Between-group analysis by independent $t$-test showed that the experimental group outperformed the control group significantly in vertical jump test $\mathrm{t}(53)=7.71 ; \mathrm{p}=.01$, Cohen's $\mathrm{d}=1.24 ; 20 \mathrm{~m}$ sprint test $\mathrm{t}(53)=5.05 ; \mathrm{p}=.03$,Cohen's $\mathrm{d}=1.12$
\end{abstract}

and in Illinois agility test $\mathrm{t}(53)=2.84 ; \mathrm{p}=.03$, Cohen's $\mathrm{d}=0.72$. This study found that SAQ training is an effective training program for improving selected sports performance measures in amateur soccer players. Addition of specialized training equipment in SAQ training can cause a significant improvement in sports performance measures. The findings of the study can assist the clinician to design the late stage of rehabilitation protocol, preseason training and conditioning in novice and semiprofessional athletes.

Keywords Preseason Training, Maximal Speed, Explosive Movements, Specialized Training Equipment

\section{Introduction}

Soccer is a randomized intermittent dynamic type sport which involves a pattern of dynamic intermittent activities performed in various intensities [1]. A professional soccer 
player performs an average of 700 turns, 40 sprints (which last for two to three seconds), $30-40$ jumps and tackles in a 90-minute soccer match [2]. These players perform several activities that require highly complex physical abilities such as agility, speed, power etc., which makes the conditioning of the players a complex process. According to Joo [3], high-speed actions in soccer require acceleration, maximal speed and agility skills, while Chapman et al. [4] describe the speed in soccer consists of running speed, reaction speed and acceleration speed. Sprint during soccer competition is performed over a shorter distance with maximal intensity and constantly changes direction [5].

Speed, agility and quickness (SAQ) are the key determinants in soccer which enable the player to address the decisive situations such as goal scoring, dribbling and winning the ball during competitions [6]. Agility along with quickness and speed in the first few steps represents the key motor ability in soccer [7]. According to Yap, Brown [8] agility, speed and acceleration are specific unrelated qualities and their training causes a limited transfer to each other. A typical SAQ training session involves explosive movements from fundamental movement pattern which progresses to highly positional specific movements. Hence this training can improve movement mechanics and enhance the length and frequency of steps [9]. Since soccer requires multidirectional physical and physiological demands, it is important to use a training method such as SAQ to promote an integrated effect, hence save energy and time [5].

Jovanovic et al. [5] and Milanović et al. [10] reported a significant improvement in the sprint and jump performance following SAQ training in elite soccer players. According to Polman et al. [11], SAQ training enables the soccer players to move effectively in various directions and to change the directions and to stop quickly during faster movements efficiently and smoothly. The authors also reported that SAQ training produced an improvement in acceleration $(6.9 \%)$ and running velocity. Rosch et al. [12] reported that SAQ training can improve soccer movements with better balance, strength, and control without losing speed. At the same time, Milanović et al. [10] reported that SAQ training was not effective in improving 20-meter sprint in young soccer players.

Several specialized training equipment is being used by the athletes and coaches for SAQ training. However, the effectiveness of this training equipment is not investigated properly. So, the purpose of this study is to investigate the effectiveness of SAQ training and to compare the SAQ training with and without specialized training equipment in amateur soccer players.

\section{Materials and Methods}

\section{Participants}

A sample consisting of 64 amateur male soccer players between the ages of 18-25 from Jamia Hamdard University participated in the study. The sample size was calculated as 26 per group to estimate a difference of 0.38 in normal 20 -meter sprint test value of $3.47 \pm 0.16$ (mean \pm SD) in amateur athletes with a power of $80 \%$ and $5 \%$ significance level based on a previous study [13]. The participant's characteristics can be seen in Table 1. Due to the difference in motor ability, the goalkeepers were excluded from the study [14]. The participants were free from any musculoskeletal and neurological impairment during testing and training period. All the participants were novice to SAQ training. Nutritional supplements were not included in their regular diet and they were advised not to take anabolic steroids or any medication which may influence their performance. Written informed consent was taken from all the participants before the test commenced and the study was approved by the institutional ethical committee of Jamia Hamdard. The participants were randomly allocated to the experimental group and the control group by an independent researcher who is not related to this study. (Figure 1). The experimental group has undergone six weeks of SAQ training with equipment and the control group has undergone six weeks of SAQ training without equipment. Detail of the SAQ training protocol given for both groups is available in table 2.

Table 1. Subjects characteristics. Values are Mean \pm SD.

\begin{tabular}{ccc}
\hline Characteristics & Exercise Group & Equipment Group \\
\hline Age $($ Years $)$ & $19.64 \pm 0.91$ & $18.57 \pm 0.50$ \\
Height $(\mathrm{cm})$ & $175.60 \pm 3.43$ & $177.14 \pm 3.36$ \\
Weight $(\mathrm{Kg})$ & $65.42 \pm 1.98$ & $66.92 \pm 1.94$ \\
\hline
\end{tabular}


Table 2. Content of the six-week SAQ training program in both groups

\begin{tabular}{|c|c|c|}
\hline Phase & Exercise group & Equipment group \\
\hline Week $1 \& 2$ & $\begin{array}{l}\quad \text { (Length Two x 20-min matches) } \\
\text { - High knee walk } \\
\text { - High knee running } \\
\text { - High knee sideways } \\
\text { - Bunny hoppings } \\
\text { - Lateral bunny hoppings } \\
\text { - Five meter length } \\
\text { - Fast foot running } \\
\text { - Burning coal running } \\
\text { - Bunny hopping } \\
\text { - Lateral fast foot running }\end{array}$ & $\begin{array}{l}\text { (Six x Six inch hurdles) } \\
\text { - Walkthroughs } \\
\text { - Run throughs } \\
\text { - Lateral run-throughs } \\
\text { - Bunny hoppings } \\
\text { - Lateral bunny hoppings } \\
\text { - Fast foot ladder } \\
\text { - One foot per square run } \\
\text { - Miss a square running } \\
\text { - Hopscotch } \\
\text { - Bunny hoppings } \\
\text { - Sideways two foot per square run }\end{array}$ \\
\hline Week $3 \& 4$ & $\begin{array}{l}\text { (Seven \& Five meter lengths) } \\
\text { - T, X, Y, H patterns } \\
\text { - Fast foot running } \\
\text { - Single leg running } \\
\text { - Sideways running } \\
\text { - Carioca dill } \\
\text { - Icky shuffle drill } \\
\text { - Ali shuffle drill } \\
\text { - Step ups (three, four ) } \\
\text { - Bunny hoppings } \\
\text { - Simple reaction drills } \\
\text { - Partner resistance drill } \\
\text { - Ten meter let gos }\end{array}$ & $\begin{array}{l}\text { (Six \& Twelve inch hurdles, fast) } \\
\text { - Foot ladder } \\
\text { - T, X, Y, H patterns } \\
\text { - two feet per square run } \\
\text { - Single leg running } \\
\text { - Lateral running } \\
\text { - Carioca drills } \\
\text { - Icky shuffle drill } \\
\text { - Ali shuffle drill } \\
\text { - Step-ups (three, four ) } \\
\text { - Bunny hopping } \\
\text { - Simple reaction drills } \\
\text { - Viper belt } \\
\text { - Ten meter running }\end{array}$ \\
\hline Week 5\&6 & $\begin{array}{l}\text { (20 meter course races) } \\
\text { - W drill } \\
\text { - N drill } \\
\text { - Zigzags } \\
\text { - Partner resistance drills } \\
\text { - Ten meter let go } \\
\text { - Let go hollow sprints } \\
\text { - Overspeed } \\
\text { - Partner drills } \\
\text { - Mirror drill } \\
\text { - Get up and go }\end{array}$ & $\begin{array}{l}\text { (Six \& Twelve inch hurdles, fast) } \\
\text { - Foot ladders, swerve cones, stride canes } \\
\text { - Twenty meter courses (races) } \\
\text { - W drill (hurdles) } \\
\text { - N drill (ladder) } \\
\text { - Zigzags } \\
\text { - Viper belt } \\
\text { - Ten meter sprints } \\
\text { - Five meter hollow sprints } \\
\text { - Overspeed } \\
\text { - Reaction ball } \\
\text { - Manic } 21 \mathrm{~s} \\
\text { - Breakaway belts } \\
\text { - Mirror drill } \\
\text { - Get up and go }\end{array}$ \\
\hline
\end{tabular}




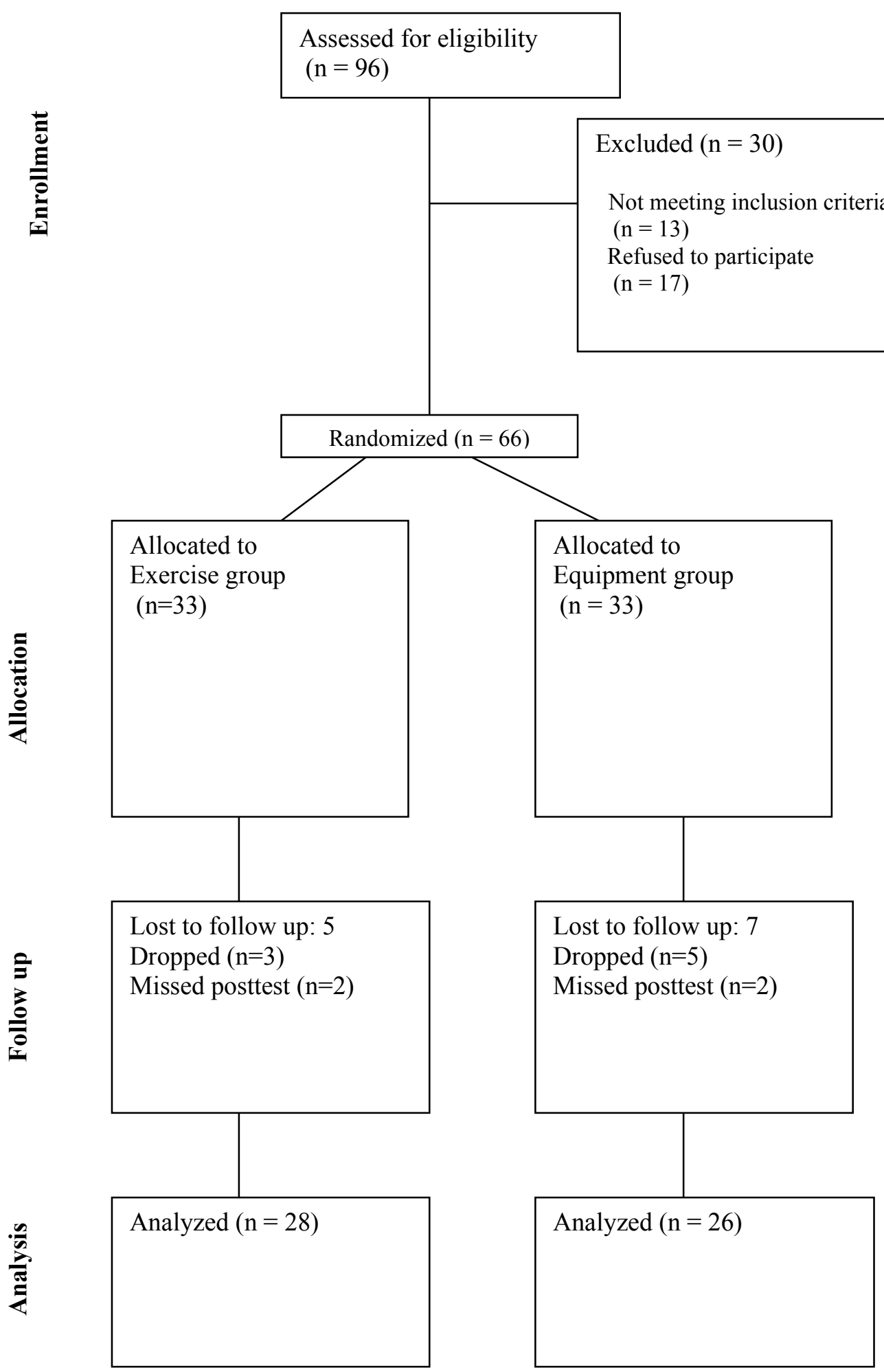

Figure 1. Consort diagram showing the flow of the participants through each stage of randomized trail 


\section{Procedure}

The design of the study was a pretest-posttest design. Each training session consists of a standard 15 minutes warm-up (light jogging, running and dynamic stretching) and an average of 45 minutes exercise session. Each participant received $14.9 \pm 2.8$ hours (mean $\pm \mathrm{SD}$ ) of training. The specialized training equipment used in the study included fast feet ladders, hurdles (6 inch \& 12 inches), breakaway belts, stride canes, reaction ball, sprint resistors, viper resistance belts and Flexi cords [15]. The content of the exercise in both groups can be seen in table 2. All the testing was conducted in the morning session and verbal encouragement was given to the participants during testing. The testing was conducted in a grass soccer field with soccer shoes to replicate the real playing conditions. To avoid fatigue effect, the participants were advised to avoid intensive exercises at least 24 hours before testing. The testing was done three times and the average was taken for analysis. The following performance assessment testing was conducted.

Vertical Jump test: The investigator used the Vertec for recording the vertical jump. The participants were standing in an upright position with hands by the side and approximately 15 centimetres away from the device. The testing was done on a non-slippery flat surface. The Vertec was adjusted depending on the standing reach of the subject which was measured with the highest level of reach while heels maintained on the floor. The participants were instructed to jump as high as possible and deflect as many bars on the Vertec as possible. Practical trials were given before testing. The investigator measured the difference between standing reach height and jumping height [13]. Three correct attempts were done, and the average was taken.

Illinois agility test: An electronic timing system was used to record the Illinois agility test. Four cones are used to mark the starting point (A), 2 turning points $(B \& C)$ and the finishing point (D). Four more cones were placed in the middle of the testing area. The distance between each central cone is 3.3 meters and the distance between cone A to $\mathrm{B}$ and $\mathrm{C}$ to $\mathrm{D}$ is 10 meters. The subjects started sprinting from cone A [16].

Twenty-meter sprint test: The subject performed a 20-meter sprint test through electronic timing gates (Omron Electronics LTD, UK). All the test was performed in a standing start with the dominant leg in front [17]

\section{Statistical analysis}

SPSS (v23.0; IBM Corporation, Armonk, NY, USA) was used for statistical analysis. The normal distribution of the data and was confirmed by the Shapiro-Wilk test $(p>0.05)$ for the use of parametric analysis and equality of the variances satisfied by Levene test $(p>0.05)$. The pretest and posttest data within each group were compared using a paired sample t-test. The independent t-test was used to compare the mean variations of the experimental and control groups. A statistically significant difference was defined as 'p' value less than 0.05 .

\section{Results}

Both the experimental and control groups were well matched $(\mathrm{p}>.05)$ in pre-test without any significant difference for variables between the groups. The pre-and post-intervention data of all the sports performance parameters are summarized in Table 3. Both groups were significantly improved $(p<.05)$ from pre to post-training in all sports performance measures. Between-group analysis by independent $\mathrm{t}$-test showed that the experimental group outperformed the control group significantly in vertical jump test $\mathrm{t}(53)=7.71 ; \mathrm{p}=.01$, Cohen's $\mathrm{d}=1.24 ; 20 \mathrm{~m}$ sprint test $\mathrm{t}(53)=5.05 ; \mathrm{p}=.03$, Cohen's $\mathrm{d}=1.12$ and in Illinois agility test $\mathrm{t}(53)=2.84 ; \mathrm{p}=.03$, Cohen's $\mathrm{d}=0.72$. 
Table 3. Pre and post-intervention data for all functional performance tests in both the experimental and control group.

\begin{tabular}{|c|c|c|c|c|c|c|c|c|c|c|c|c|}
\hline \multirow{3}{*}{ Performance tests } & \multicolumn{6}{|c|}{ Control Group } & \multicolumn{6}{|c|}{ Experimental Group } \\
\hline & \multirow{2}{*}{ Pre } & \multirow{2}{*}{ Post } & \multirow{2}{*}{ P-value } & \multirow{2}{*}{$\mathrm{T}$ value } & \multicolumn{2}{|c|}{$95 \%$ CI of difference } & \multirow{2}{*}{ Pre } & \multirow{2}{*}{ Post } & \multirow{2}{*}{ P-value } & \multirow{2}{*}{$\mathrm{T}$ value } & \multicolumn{2}{|c|}{$95 \% \mathrm{CI}$ of difference } \\
\hline & & & & & Upper & Lower & & & & & Upper & Lower \\
\hline $\begin{array}{l}\text { Vertical jump } \\
\text { test }(\mathrm{cm})\end{array}$ & $43.37 \pm 8.56$ & $44.76 \pm 8.06$ & $.001^{*}$ & 4.05 & -2.09 & -0.68 & $42.85 \pm 3.19$ & $46.68 \pm 3.88$ & $.005^{*}$ & 16.63 & -3.35 & -16.33 \\
\hline $20 \mathrm{~m}$. sprint test $(\mathrm{S})$ & $3.46 \pm 0.20$ & $3.37 \pm 0.25$ & $.002^{*}$ & -3.04 & 0.04 & 0.20 & $3.52 \pm 0.13$ & $3.09 \pm 0.19$ & $.000^{*}$ & -18.22 & 0.48 & 18.22 \\
\hline Illinois test(S) & $16.43 \pm 0.51$ & $16.25 \pm 0.53$ & $.012^{*}$ & -2.50 & 0.01 & 0.25 & $16.41 \pm 0.13$ & $15.95 \pm 0.12$ & $.034^{*}$ & -14.81 & 7.49 & 14.87 \\
\hline
\end{tabular}

Values are Mean $\pm \mathrm{SD}$; $\mathrm{CI}=$ confidence interval 


\section{Discussion}

Result of the study showed that six weeks of SAQ training have a positive impact on sports performance parameters. SAQ training can be used as a useful tool in improving sports performance parameters. A similar improvement in sports performance was observed in previous studies $[18,19,12,20]$. It can cause an improvement in agility [20] and sprinting speed [10]. Rosch et al. [12] reported that soccer players were able to adapt their body position and were able to perform soccer movements with a better balance, strength, and control without compromising the speed following SAQ training. According to Trecroci et al. [19], SAQ training can positively influence cognitive skills and sprint performance in sub-elite junior soccer players. It can also be noted in our study that the significant improvement in sports performance parameters took place in a shorter period in individuals who never undergone SAQ training.

Ability to perform running over a short distance at maximal speed is an indispensable component in soccer performance $[21,22]$. It is the most frequent action before goal scoring for both scoring and assisting the other player to score $[23,24]$. Around $90 \%$ of the sprints during soccer matches are around or shorter than 20 meters [25]. The improvement in sprinting speed in both groups may be due to the specificity of footwork exercises such as skip and multiple hops, with a short contact time with the exercising surface. These conditions can also cause higher force production in the lower limb muscles leading to an increase in power [15].

Ability to make rapid and effective changes in direction which is referred to as agility is a key prerequisite for soccer which has to be trained and monitored in soccer players [26]. In many situations during soccer demands a rapid change in direction. Agility represents an important performance determinant in soccer which must be included in regular training [27]. According to Pearson [9], SAQ training method consists of exercises which can influence all the four elements of agility such as balance, coordination, programmed and random agility. Illinois test has been considered as a valid test to measure the agility in sports person [28]. An improvement in leg power and speed also influences the result of the agility test [15]

Another sports performance parameter which was assessed in the current study was the vertical jump performance which is considered as a predictor for lower limb power. Lower limb power is crucial in soccer players in both attack and defence when goals are either scored or defended. According to Krustrup et al. [29] success in soccer is directly related to the power performance and thus emphasized the importance of SAQ training in soccer players. Jumping action is also important in certain decisive situations such as goal scoring and the researchers recommend that it should be included in fitness testing and training of soccer players [24].
Even though the current study does not investigate the underlying mechanism behind the improvement of performance following SAQ training some suggestions can be made, the specificity of exercise in both SAQ program and both groups received drills which improve the movement mechanics might have caused the development of better functional and motor program which control complex neuromuscular coordination associated with sports performance activities. Additionally, an obvious relationship between some of the variables measured in the current study was in some of the previous researches. Wisløff et al. [30] reported a strong correlation between lower limb power, sprinting speed and vertical jump performance in elite soccer players. Cronin, Hansen [31] reported that a faster athlete has a higher test value of power performance parameters such as squat jump and countermovement jump. Pauole et al. [32] reported a significant correlation of agility with sprinting speed in collegiate athletes. At the same time, Buttifant et al. [33] and Young et al. [34] reported no correlation between sprinting speed and agility parameters in football players. The improvement in speed which is measured by 20 -meter sprint test can be partially related to the improvement measured in vertical jump performance. Enhancement in lower limb power in our study might have resulted in a reduced contact time of the feet on sprinting surface and production of high forces in the lower limb muscles at a faster rate.

One of the most important findings of the study was that the athletes who have undergone SAQ training with specialized equipment were improved significantly when compared to the athletes who have undergone training without equipment. The specialized equipment which was used for SAQ training might have acted as an obstacle in the experimental group, thus providing a visual sensory input for the participants and hence improved their drills with more precise, coordinated, and fast movements with fewer errors enhancing their sports performance. Moreover, the higher improvement in performance in subjects who have undergone SAQ training with equipment may be due to a placebo effect. The participants in the experimental group were using specialized equipment which might have enhanced their motivation compared with the control group.

One of the limitations of the study is that even though the SAQ training program reported a positive impact of sports performance measures its effectiveness on actual game performance is not measured in the current study. Further researches are recommended for the comparison of the effectiveness of SAQ training in a match environment. Secondly, amateur soccer players between the ages of 18- 25 participated in the study. So, the result cannot be generalized to other population. Thirdly, even though the verbal motivation was given to the participants during training and testing no attempt was made to find out the motivational level of the participants. Another 
limitation of the study is that the current study does not investigate the underlying mechanism of improvement in sports performance variables. Further research is recommended using laboratory methods such as electromyography and tensiomyography to progress the findings of the current study into a more theoretical level.

\section{Conclusions}

Based on the findings of this study it can be concluded that the SAQ training is an effective way to improve sports performance parameters in amateur athletes and addition of specialized equipment can lead to better improvement in performance. The findings of the study can assist the clinician to design the late stage of rehabilitation protocol, preseason training and conditioning in novice and semiprofessional athletes.

\section{Acknowledgments}

The author would like to thank all the participants of the study.

\section{Source of Funding}

This research did not receive any specific grant from funding agencies in public, commercial, or not-for-profit sectors.

\section{REFERENCES}

[1] A. I. Shaikh, S. Nuhmani, S. J. Kachanathu, and Q. I. Muaidi, "Relationship of Core Power and Endurance with Performance in Random Intermittent Dynamic Type Sports," Asian Journal of Sports Medicine, vol. 10, no. 1, 2019. DOI: 10.5812/asjsm.62843

[2] J. Bloomfield, R. Polman, and P. O'Donoghue, "Physical demands of different positions in FA Premier League soccer," Journal of sports science \& medicine, vol. 6, no. 1, pp. 63, 2007.

[3] C. H. Joo, "The effects of short term detraining and retraining on physical fitness in elite soccer players," PloS one, vol. 13, no. 5, pp. e0196212, 2018. DOI: 10.1371/journal.pone.0196212

[4] S. Chapman, E. Derse, and J. Hansen, "Soccer coaching manual," Los Angeles: LA84 Foundation, 2008.

[5] M. Jovanovic, G. Sporis, D. Omrcen, and F. Fiorentini, "Effects of speed, agility, quickness training method on power performance in elite soccer players," The Journal of Strength \& Conditioning Research, vol. 25, no. 5, pp. 1285-1292, 2011. DOI: 10.1519/JSC.0b013e3181d67c65

[6] R. Hammami, I. Makhlouf, M. Chtara, J. Padulo, and A.
Chaouachi, "The contribution of vertical explosive strength to sprint performance in children," Sport Sciences for Health, vol. 11, no. 1, pp. 37-42, 2015. DOI: $10.1007 / \mathrm{s} 11332-014-0200-2$

[7] J. Weineck, "Optimal training," Perugia, Italy: Calzetti Mariucci, 2009.

[8] C. W. Yap, and L. E. Brown, "Development of speed, agility, and quickness for the female soccer athlete," Strength \& Conditioning Journal, vol. 22, no. 1, pp. 9, 2000. DOI: 10.1519/00126548-200002000-00002

[9] A. Pearson, Soccer fitness: more than 100 drills for speed, agility, and quickness: Contemporay Books, 2001.

[10] Z. Milanović, G. Sporiš, N. Trajković, D. Sekulić, N. James, and G. Vučković, "Does SAQ training improve the speed and flexibility of young soccer players? A randomized controlled trial," Human movement science, vol. 38, pp. 197-208, 2014. DOI: 10.1016/j.humov.2014.09.005

[11] R. Polman, J. Bloomfield, and A. Edwards, "Effects of SAQ training and small-sided games on neuromuscular functioning in untrained subjects," International journal of sports physiology and performance, vol. 4, no. 4, pp. 494-505, 2009. DOI: 10.1123/ijspp.4.4.494

[12] D. Rosch, R. Hodgson, L. Peterson, T. Graf-Baumann, A. Junge, J. Chomiak, and J. Dvorak, "Assessment and evaluation of football performance," The American journal of sports medicine, vol. 28, no. 5 suppl, pp. 29-39, 2000. DOI: 10.1177/28.suppl_5.s-29

[13] A. Nawed, I. A. Khan, J. Jalwan, S. Nuhmani, and Q. I. Muaidi, "Efficacy of FIFA 11+ training program on functional performance in amateur male soccer players," Journal of back and musculoskeletal rehabilitation, vol. 31, no. 5 , pp. 867-870, 2018. DOI: 10.3233/BMR-171034

[14] H. Taskin, "Evaluating sprinting ability, density of acceleration, and speed dribbling ability of professional soccer players with respect to their positions," The Journal of Strength \& Conditioning Research, vol. 22, no. 5, pp. 1481-1486, 2008.

[15] J. Bloomfield, R. Polman, P. O'Donoghue, and L. McNaughton, "Effective speed and agility conditioning methodology for random intermittent dynamic type sports," Journal of Strength and Conditioning Research, vol. 21, no. 4, pp. 1093, 2007. DOI: 10.1519/R-20015.1

[16] K. Goral, "Examination of agility performances of soccer players according to their playing positions," Sport J, vol. 1, 2015.

[17] L. Reinhardt, R. Schwesig, A. Lauenroth, S. Schulze, and E. Kurz, "Enhanced sprint performance analysis in soccer: New insights from a GPS-based tracking system," PloS one, vol. 14, no. 5, pp. e0217782, 2019. DOI: 10.1371/journal.pone.0 217782

[18] S. A. Mohamed, and A. Larion, "Effect of SAQ training on certain physical variables and performance level for sabre fencers," Ovidius University Annals, Series Physical Education \& Sport/Science, Movement \& Health, vol. 18, no. $1,2018$.

[19] A. Trecroci, Z. Milanović, A. Rossi, M. Broggi, D. Formenti, and G. Alberti, "Agility profile in sub-elite under-11 soccer 
players: is SAQ training adequate to improve sprint, change of direction speed and reactive agility performance?," Research in Sports Medicine, vol. 24, no. 4, pp. 331-340, 2016. DOI: $10.1080 / 15438627.2016 .1228063$

[20] Z. Milanović, G. Sporiš, N. Trajković, N. James, and K. Šamija, "Effects of a 12 week saq training programme on agility with and without the ball among young soccer players," Journal of sports science \& medicine, vol. 12, no. 1, pp. 97, 2013.

[21] Bin Shamshuddin, M.H., Hasan, H., Azli, M.S., Mohamed, M.N. and Razak, F.A.A., 2020. "Effects of plyometric training on speed and agility among recreational football players". International Journal of Human Movement and Sports Sciences, vol. 8, no. 5, pp. 174-80, 2020. DOI: 10.13189/saj.2020.080503

[22] M. Tomáš, Z. František, M. Lucia, and T. Jaroslav, "Profile, correlation and structure of speed in youth elite soccer players," Journal of human kinetics, vol. 40, no. 1, pp. 149-159, 2014. DOI: 10.2478/hukin-2014-0017

[23] T. A. Haugen, E. Tønnessen, J. Hisdal, and S. Seiler, "The role and development of sprinting speed in soccer," International journal of sports physiology and performance, vol. 9, no. 3, pp. 432-441, 2014. DOI: 10.1123/ijspp.2013-0121

[24] O. Faude, T. Koch, and T. Meyer, "Straight sprinting is the most frequent action in goal situations in professional football," Journal of sports sciences, vol. 30, no. 7, pp. 625-631, 2012. DOI: 10.1080/02640414.2012.665940

[25] G. Vigne, C. Gaudino, I. Rogowski, G. Alloatti, and C. Hautier, "Activity profile in elite Italian soccer team," International journal of sports medicine, vol. 31, no. 05, pp. 304-310, 2010. DOI: $10.1055 / \mathrm{s}-0030-1248320$

[26] M. Slimani, and P. T. Nikolaidis, "Anthropometric and physiological characteristics of male Soccer players according to their competitive level, playing position and age group: a systematic review," J Sports Med Phys Fitness, pp. 07950-6, 2017. DOI: 10.23736/S0022-4707.17.07950-6

[27] C. Lupo, A. N. Ungureanu, M. Varalda, and P. R. Brustio, "Running technique is more effective than soccer-specific training for improving the sprint and agility performances with ball possession of prepubescent soccer players," Biology of Sport, vol. 36, no. 3, pp. 249, 2019. DOI: 10.5114/biolsport.2019.87046

[28] M. A. Raya, R. S. Gailey, I. A. Gaunaurd, D. M. Jayne, S. M. Campbell, E. Gagne, P. G. Manrique, D. G. Muller, and C. Tucker, "Comparison of three agility tests with male servicemembers: Edgren Side Step Test, T-Test, and Illinois Agility Test," Journal of Rehabilitation Research \& Development, vol. 50, no. 7, 2013. DOI: 10.1682/JRRD.20 12.05.0096

[29] P. Krustrup, M. Mohr, H. Ellingsgaard, and J. Bangsbo, "Physical demands during an elite female soccer game: importance of training status," Medicine and science in sports and exercise, vol. 37, no. 7, pp. 1242, 2005. DOI: 10.1249/01.mss.0000170062.73981.94

[30] U. Wisløff, C. Castagna, J. Helgerud, R. Jones, and J. Hoff, "Strong correlation of maximal squat strength with sprint performance and vertical jump height in elite soccer players," British journal of sports medicine, vol. 38, no. 3, pp. 285-288, 2004. DOI: $10.1136 /$ bjsm.2002.002071

[31] J. B. Cronin, and K. T. Hansen, "Strength and power predictors of sports speed," J Strength Cond Res, vol. 19, no. 2, pp. 349-357, 2005. DOI: 10.1519/00124278-20050500000019

[32] K. Pauole, K. Madole, J. Garhammer, M. Lacourse, and R. Rozenek, "Reliability and validity of the T-test as a measure of agility, leg power, and leg speed in college-aged men and women," The Journal of Strength \& Conditioning Research, vol. 14, no. 4, pp. 443-450, 2000. DOI: 10.1519/00124278-200011000-00012

[33] D. Buttifant, K. Graham, and K. Cross, "55 agility and speed in soccer players are two different performance parameters," Science and football IV, pp. 329, 2001.

[34] W. Young, R. James, and I. Montgomery, "Is muscle power related to running speed with changes of direction?," Journal of Sports Medicine and Physical Fitness, vol. 42, no. 3, pp. 282-288, 2002. 